\title{
Effects of Early Warning Score (EWS) Tutorial Simulation on Nurses' Knowledge and Clinical Performance
}

\author{
Roshy Damayanti ${ }^{1}$, Yanny Trisyani ${ }^{2}$, Aan Nuraeni ${ }^{2}$ \\ ${ }^{1}$ Master Program in Nursing, Faculty of Nursing, Universitas Padjadjaran, Indonesia \\ ${ }^{2}$ Faculty of Nursing, Universitas Padjadjaran, Indonesia \\ Corresponding Author: Roshy Damayanti (roshydamayanti.85@gmail.com)
}

\begin{abstract}
Background: The Early Warning Score (EWS) system has been recommended for an early identification tool of deterioration. However, its implementation has not been optimal, one of which is due to the low level of knowledge and understanding of EWS among nurses.

Purpose: This study aimed to determine the effects of EWS tutorial simulation on nurses' knowledge and clinical performance.

Methods: This study employed a pretest-posttest quasi-experimental design with a control group. Purposive sampling was used to recruit samples of 42 respondents each in the intervention group and control group. The data were collected using the questionnaires to measure knowledge and clinical performance and analyzed using Chi-square, Wilcoxon, and Mann-Whitney tests.

Results: The results showed that there were significant differences in the pre-test and post-test of knowledge and clinical performance in both groups $(p<0.001)$. There was also a significant difference in clinical performance between the intervention group and the control group $(p<0.001)$. However, no significant difference in knowledge was found.

Conclusion: Tutorial simulation of EWS had an effect on increasing nurses' clinical performance. Although there was no significant difference in knowledge between the intervention group and the control group, the intervention group showed a better value than the control group. EWS tutorial simulation can be used as one of the training methods to increase nurses' knowledge and clinical performance in EWS.
\end{abstract}

Keywords: Early warning score; clinical performance; knowledge; tutorial simulation

How to cite: Damayanti, R., Trisyani, Y., \& Nuraeni, A. (2019). Effects of early warning score (EWS) tutorial simulation on nurses' knowledge and clinical performance. Nurse Media Journal of Nursing, 9(2), 231-242. doi:10.14710/nmjn.v9i2.24821

Permalink/DOI: https://doi.org/10.14710/nmjn.v9i2.24821

\section{BACKGROUND}

The care needs of patients with the acute illness have increased with the complexity of existing problems. Such conditions can trigger clinical deterioration that may develop into Serious Adverse Events (SAEs), such as cardiac arrest, unintended Intensive Care 
Unit (ICU) admissions, as well as unexpected and preventable deaths (Taenzer, Pyke, \& McGrath, 2011). A majority of SAEs begin with abnormal physiological changes and can develop into critical illness later (Corfield et al., 2014; Fagan, Sabel, Mehler, \& MacKenzie, 2012). Early detection and appropriate interventions are important in improving the safety and effectiveness of care in patients with clinical signs of worsening (Alam et al., 2015).

Early Warning Score (EWS) system is a bedside tool developed for early identification of physiological deterioration by establishing numerical values of physiological parameters in which the results can be used to see the patient's condition; EWS is able to predict who is at risk of critical illness (Corfield et al., 2014). The implementation of EWS has not been optimal so far due to several obstacles, including poor understanding of physiological deterioration and triggering criteria (De Meester, Verspuy, Monsieurs \& Van Bogaert, 2013); delays in recognition of staffs to worsening clinical condition of patients, which is associated with the level of knowledge and understanding of EWS (Bick et al., 2014); failure to complete and measure reliable vital signs, errors in calculating the EWS scores (Ludikhuize, Smorenburg, de Rooij, \& de Jonge, 2012); ineffectiveness of communication (Rabøl, Andersen, Østergaard, Bjørn, Lilja, \& Mogensen, 2011); and weak clinical reasoning skills (Lapkin, Levett-jones, \& Bellchambers, 2010).

Educational programs have been developed to assist staff in recognizing and managing worsening patient conditions, but lack of studies that evaluate the effects of educational programs on knowledge and clinical performance. The quality of nursing competence requires good performance in various nursing services. Nurses not only require adequate knowledge and skill in carrying out their duties and responsibilities, but they need to transform it into effective performance (Zhang, Luk, Arthur, \& Wong, 2001) as actual performance is the most important outcome of education (Bradshaw \& Hultquist, 2017; Khan \& Ramachandran, 2012). Furthermore, Saab et al. (2017) suggest that EWS education programs can be used to increase nurse knowledge, self-confidence, and clinical performance.

A preliminary study conducted by the researchers in one of the hospitals in Indonesia showed that the implementation of EWS was still suboptimal. Furthermore, incorrect calculation of the EWS scores, as well as a non-standardized understanding of the EWS among nurses, were still found. Research on EWS training with tutorial simulation to increase nurses' knowledge and clinical performance has not been extensively investigated. Therefore, it is indeed necessary to investigate how such simulation affects nurses' knowledge and clinical performance.

\section{PURPOSE}

The purpose of this study was to determine the effects of EWS tutorial simulation on nurses' knowledge and clinical performance. 


\section{METHODS}

\section{Research design}

The present study used a pretest-posttest quasi-experimental research design with a control group.

\section{Samples and setting}

This study was conducted at one hospital in Indonesia. A purposive sampling method was utilized to recruit the samples of nurses who met the inclusion criteria: working in an adult inpatient room, never receiving EWS training, and had been working for at least two years. Forty-two respondents who met the inclusion criteria in each of the intervention group and the control group participated in this study.

\section{Research instrument and data collection}

The instruments used in this study were the knowledge questionnaire and the Rescuing a Patient in Deteriorating Situations tool (RAPIDS tool). The knowledge questionnaire consisted of respondents' characteristics and 20 questions related to the concept and implementation of the EWS in handling patients showing signs of deterioration. This questionnaire was developed in accordance with the New Early Warning Score (NEWS) guidelines based on the Royal College of Physician (2017) and National Clinical Effectiveness Committee (2014). The questionnaire is a linked scale (1-5) with a total score of 100.

The instrument used to measure clinical performance was the modified RAPIDS tool (Liaw, Chan, Chen, Hooi, \& Siau, 2014). RAPIDS tool is an instrument for measuring the clinical performance of respondents in early detection of changes in vital signs, nursing assessments and interventions through Airway, Breathing, Circulation, Disability, Exposure/Examinations (A, B, C, D, E) and reported clinical deterioration using ISBAR communication. The RAPIDS modification tool consisted of three parts. Part 1 contained the assessment of clinical deterioration with ABCDE. Part 2 contained the clinical response of nurses in dealing with patients with or at risk of worsening clinical conditions. This integrated clinical judgment (demonstrated by the ability to determine appropriate EWS scores), critical thinking, and clinical reasoning could be seen in the actions of nurses in following up deterioration and monitoring frequency. Part 3 contained communication using ISBAR to see nurses' expertise in reporting patient conditions. Permission to use the RAPIDS tools was obtained from the instrument's owner (Liaw et al., 2014), for which the validity and reliability of the instrument had been carried out. The original instrument was then translated and modified by adjusting the instrument points with the latest EWS concept, updated NEWS 2017, and consulted with expert judgment. Validity testing using expert judgment was carried out on two experts by examining the question items. The knowledge questionnaire was tested for validity using Pearson's product moments with computer aids. Based on the validity test on the knowledge questionnaire, all 20 question items were valid. The reliability test was carried out using the formula Kuder Richardson 20 (KR-20) and the instrument was reliable.

Pre-test and post-test on both groups were conducted on the same day. All respondents both in the intervention group and the control group were separately collected in the training room to take a 20-minute knowledge and clinical performance using the 
knowledge questionnaires. The EWS tutorial simulation was administered in the intervention group sequentially. First, the EWS tutorial was given to all respondents for 90 minutes, then continued with a 60 -minute case simulation. The simulation was given to the respondents in three large groups by the researchers and two trained research assistants. The control group received the EWS tutorial training for 90 minutes without case simulations.

\section{Data analysis}

Univariate and bivariate analyses were conducted in this study. Data processed using the univariate analysis were general information on the characteristics of respondents. Bivariate analysis was used to determine the relationship between independent and dependent variables. Data analysis began with conducting data normality tests using Shapiro-Wilk as the number of respondents was less than 50 respondents in each group. The results of the normality test showed that the existing data, both knowledge, and clinical performance, had an abnormal distribution. Furthermore, the Wilcoxon test was used to see differences between the pre-test and post-test of knowledge and clinical performance within groups, while the Mann-Whitney test was used to see differences in the pre-test and post-test of knowledge and clinical performance between groups.

\section{Ethical consideration}

Prior to the study, all respondents expressing agreement to participate in the study were informed of the objectives, benefits, and procedures of the research. They were also requested to sign informed consent. Respecting the privacy and confidentiality of respondents, providing training fairly, providing benefits, and avoiding dangerous actions were ensured during the study. This research had been reviewed and obtained ethical permission from the ethics and research committee in the Faculty of Nursing, Universitas Padjadjaran, Bandung, Indonesia.

\section{RESULTS}

\section{Characteristics of respondents}

The results of the study, as presented in Table 1, showed that more than half of the respondents in the intervention group and the control group were women and aged 30 to 39 years. A majority of respondents in both groups hold diploma education and had working experiences of less than five years. The characteristic data, both in the intervention and control groups, were not significantly different $(p>0.05)$.

Table 1. Characteristics of respondents $(n=84)$

\begin{tabular}{lrrrr}
\hline \multirow{2}{*}{ Category } & \multicolumn{2}{c}{ Intervention } & \multicolumn{2}{c}{ Control } \\
\cline { 2 - 5 } & \multicolumn{1}{c}{$f$} & $\%$ & \multicolumn{1}{c}{$f$} & $\%$ \\
\hline Gender & 15 & 35.7 & 16 & 38.1 \\
$\quad$ Male & 27 & 64.3 & 26 & 61.9 \\
$\quad$ Female & & & & \\
Age & 15 & 35.7 & 15 & 35.7 \\
$\quad<30$ years old & 23 & 54.8 & 22 & 52.4 \\
30-39 years old & 4 & 9.5 & 5 & 11.9 \\
$\quad \geq 40$ years old & & & & \\
\hline
\end{tabular}




\begin{tabular}{lrrrr}
\hline \multirow{2}{*}{ Category } & \multicolumn{2}{c}{ Intervention } & \multicolumn{2}{c}{ Control } \\
\cline { 2 - 5 } & \multicolumn{1}{c}{$f$} & $\%$ & $f$ & $\%$ \\
\hline Educational attainment & 34 & 81 & 28 & 66.7 \\
$\quad$ Diploma & 8 & 19 & 14 & 33.3 \\
$\quad$ Bachelor's degree & & & & \\
Length of work experience & 29 & 69 & 27 & 64.3 \\
$\quad$ Less than 5 years & 13 & 31 & 15 & 35.7 \\
$\quad$ More than 5 years & & & & \\
\hline
\end{tabular}

\section{Differences in knowledge}

The results in Table 2 show that there was no significant difference in the pre-test value of knowledge between the intervention group and the control group $(p=0.100)$. The knowledge significantly increased in both groups after the implementation of EWS tutorial simulation $(p<0.001)$, but there was no difference in knowledge between the intervention and control group $(p=0.195)$. However, the intervention had a higher increase in knowledge percentage than the control group.

Table 2. Differences between pre-test and post-test of knowledge $(n=84)$

\begin{tabular}{|c|c|c|c|}
\hline \multirow{2}{*}{ Knowledge } & \multicolumn{2}{|c|}{ Group } & \multirow[t]{2}{*}{$p^{*}$} \\
\hline & Intervention & Control & \\
\hline \multicolumn{4}{|l|}{ Pre-test: } \\
\hline Median & 50 & 45 & 0.100 \\
\hline Minimal - Maximal & $30-70$ & $25-80$ & \\
\hline \multicolumn{4}{|l|}{ Post-test: } \\
\hline Median & 75 & 65 & 0.001 \\
\hline Minimal - Maximal & $60-90$ & $40-90$ & \\
\hline \multicolumn{4}{|c|}{ Delta Differences within Groups } \\
\hline Pre-test vs Post-test & $\mathrm{p}^{* *}<0.001$ & $\mathrm{p}^{* *<0}<001$ & \\
\hline \multicolumn{4}{|c|}{ Delta Differences between Groups } \\
\hline Mean & -22.62 & -19.05 & 0.195 \\
\hline Percentage & $50.25 \%$ & $49.14 \%$ & \\
\hline
\end{tabular}

As presented in Table 3, before the intervention, a majority of respondents both in the intervention group and control group had a poor level of knowledge, i.e., $64.2 \%$ and $85.7 \%$, respectively. After the intervention, a majority of respondents in the intervention group had a good level of knowledge $(57.1 \%)$, while the control group had an intermediate level of knowledge (52.4\%).

\section{Differences in clinical performance}

There was no significant difference in the pre-test value of clinical performance between the intervention group and the control group $(p=0.323)$. The clinical performance scores significantly increased in both groups after the implementation of EWS tutorial simulation $(p<0.001)$. Likewise, there was a significant difference in clinical performance scores between the intervention and control group $(p=0.001)$, in which the increase of 
clinical performance in the intervention group was almost double compared to the control group (Table 4).

Table 3. Knowledge of pre-test and post-test by category $(n=84)$

\begin{tabular}{|c|c|c|c|c|c|c|}
\hline \multirow{3}{*}{ Category } & \multicolumn{2}{|c|}{ Pre-test } & \multirow{3}{*}{$p$} & \multicolumn{2}{|c|}{ Post-test } & \multirow{3}{*}{$p$} \\
\hline & Intervention & Control & & Intervention & Control & \\
\hline & $f(\%)$ & $f(\%)$ & & $f(\%)$ & $f(\%)$ & \\
\hline \multicolumn{7}{|l|}{ Knowledge } \\
\hline Good $(\geq 75 \%)$ & $2(4.8)$ & $2(4.8)$ & & $24(57.1)$ & $8(19)$ & \\
\hline Intermediate $(60-74 \%)$ & $13(31)$ & $4(9.5)$ & 0.49 & $18(42.9)$ & $22(52.4)$ & 0.001 \\
\hline Poor $(<60 \%)$ & $27(64.2)$ & $36(857)$ & & $0(0)$ & $12(28.6)$ & \\
\hline
\end{tabular}

The difference in clinical performance scores between the intervention and control group is presented in Table 4.

Table 4. Differences between pre-test and post-test of clinical performance $(n=84)$

\begin{tabular}{|c|c|c|c|}
\hline \multirow{2}{*}{ Clinical performance } & \multicolumn{2}{|c|}{ Group } & \multirow[t]{2}{*}{$p^{*}$} \\
\hline & Intervention & Control & \\
\hline \multicolumn{4}{|l|}{ Pre-test } \\
\hline Median & 52 & 50 & \multirow[t]{2}{*}{0.323} \\
\hline Minimal-maximal & $44-60$ & $40-60$ & \\
\hline \multicolumn{4}{|l|}{ Post-test } \\
\hline Median & 74 & 64 & \multirow[t]{2}{*}{0.001} \\
\hline Minimal-maximal & $60-84$ & $52-68$ & \\
\hline \multicolumn{4}{|c|}{ Delta differences within groups } \\
\hline Pre-test vs. post-test & $p^{* *}<0.001$ & \multicolumn{2}{|l|}{$p^{* *<0.001}$} \\
\hline \multicolumn{4}{|c|}{ Delta differences between groups (pre-test vs. post-test) } \\
\hline Mean & -5.45 & -2.76 & \multirow[t]{2}{*}{0.001} \\
\hline Percentage & $42.44 \%$ & $21.62 \%$ & \\
\hline
\end{tabular}

Notes: *Mann-Whitney; **Wilcoxon

\section{Clinical performance related to Early Warning Score}

Based on Table 5, it can be seen that the pre-test results of clinical performance in the intervention group and the control group were almost the same. There was a significant difference in the posttest results of clinical performance between the intervention and the control groups $(p=0.012)$.

Table 5. Clinical performance of pre-test and post-test based on category $(n=84)$

\begin{tabular}{|c|c|c|c|c|c|c|}
\hline \multirow{3}{*}{ Category } & \multicolumn{2}{|c|}{ Pre-test } & \multirow{3}{*}{$p$} & \multicolumn{2}{|c|}{ Post-test } & \multirow{3}{*}{$p$} \\
\hline & Intervention & Control & & Intervention & Control & \\
\hline & $f(\%)$ & $f(\%)$ & & $f(\%)$ & $f(\%)$ & \\
\hline \multicolumn{7}{|l|}{ Clinical Performance } \\
\hline Good ( $\geq 90 \%)$ & $0(0)$ & $0(0)$ & & $7(16.7)$ & $0(0)$ & \\
\hline Intermediate (50-89\%) & $28(66.7)$ & $28(66.7)$ & 1 & $35(83.3)$ & $42(100)$ & 0.012 \\
\hline Poor $(<50 \%)$ & $14(33.3)$ & $14(33.3)$ & & $0(0)$ & $0(0)$ & \\
\hline
\end{tabular}




\section{DISCUSSION}

\section{Effects of EWS simulation tutorial on knowledge}

This study showed that pre-test knowledge was mostly in the poor category, both in the intervention group and in the control group. In the post-test, the intervention group and control group showed an increase in the good category by $57.1 \%$ and $19 \%$, respectively. There was a significant difference in the pre-test and post-test knowledge within groups, both in the intervention group and in the control group. In contrast, there was no significant difference in the pre-test and post-test knowledge values between the intervention group and the control group.

Based on the results of this study, it can be seen that EWS tutorial simulation could increase nurses' knowledge related to EWS, although there was no statistically significant difference in effects when compared to the control group. It may be noted that the posttest score of knowledge in the intervention group was better than the control group. Jeffries (2016) stated that outcomes in nursing education are knowledge, performance skills, learner satisfaction, critical thinking, and self-confidence. This is supported by Cahill et al. (2011) that the educational program carried out for handling worsening patient conditions by introducing a new chart (A, B, C, D with AVPU) in observation proved to be able to increase nurses' compliance in filling (recording) vital signs.

Tutorial learning (lecture) is a method needed to get abstract conceptual, while for concrete experiences, it is easy to get with simulations (Billings \& Halstead, 2016). Simulations will encourage the application of knowledge and skills in real care settings. Therefore, simulations require basic knowledge that must be possessed by respondents in advance so that they can carry out clinical skills and have the ability to apply case handling algorithms (Curtin, Finn, Czosnowski, Whitman, \& Cawley, 2011).

The intervention group received training in the form of a tutorial with a simulation of a case. The insignificant difference in increasing knowledge between the intervention group and the control group was different from other studies. Research conducted by Ozekcin, Tuite, Willner, and Hravnak (2015) showed that giving a tutorial before simulation is expected to increase respondents' knowledge, as cognitive processes precede decisions to act, whereas simulation programs are widely used to teach psychomotor skills and hone clinical decision-making abilities (Gantt, 2010; Ogilvie, Cragg, \& Foulds, 2011). It is in line with Law (2014), which states that the simulation model has a significant impact on clinical performance.

\section{Effects of EWS simulation tutorials on clinical performance}

Based on this study, it was found that the pre-test clinical performance was mostly in the intermediate category, both in the intervention group and the control group, but in the post-test, the intervention group showed an increase in the good category by $16.7 \%$, while the control groups were all in enough categories. Differences in the difference between pre-test and post-test clinical performance in groups showed $p<0.001$. The EWS simulation tutorial has a better effect on clinical performance than the EWS tutorial. These results are in line with Law's (2014) study, which states that simulation models have a significant impact on clinical performance. This is also supported by Liaw et al. (2016), which state that educational programs related to patient aids in worsening 
situations can improve nurses' knowledge and clinical performance in the inpatient room in handling clinical deterioration of patients in a simulation setting. There are five categories of clinical competence in nurses, namely, clinical expertise, knowledge and understanding, interpersonal attributes, problem solving and clinical decisions, and technical expertise (Zhang et al., 2001). The interaction between knowledge and skill will encourage the realization of excellent performance (Boyatzis, 1982).

The results of this study also reinforce previous research, reporting that providing education or EWS tutorial training in the control group and EWS simulation tutorial in the intervention group caused changes in the form of increased knowledge and clinical performance of nurses, especially in the handling of worsening clinical conditions of patients. Today nurses do not only require adequate knowledge and skills in carrying out their duties and responsibilities but must be able to transform effective performance in every new situation (Lindsey \& Jenkins, 2013; Saab et al., 2017). The need for knowledge and good clinical performance from nurses increases along with the reality that all acute care in hospitals has now increased the number of patients with complex health problems. In other words, there is an increase in the number of patients at risk of worsening clinical conditions, which if not handled properly and correctly, will lead to Serious Adverse Events (SAE'S) such as cardiac arrest in hospitals, unintended ICU admissions, and unexpected deaths (Taenzer et al., 2011). In fact, most of SAE'S is preceded by signs of deterioration, which is in the form of changes in vital signs (Fagan et al., 2012). Therefore, SAE's should not have happened or at least preventable occurrence rates.

The EWS tutorial-simulation combines two learning methods, namely tutorial, and simulation. This is in line with Scalese, Obeso, and Issenberg (2008), who claim that the actual clinical meeting model is a simulation because this method provides an opportunity for educators to evaluate the clinical performance of participants in a simulated environment. It is also supported by Meakim et al. (2013) that clinical simulation requires participants in education to have clinical knowledge in advance, so they can demonstrate clinical skills, and have the ability to apply case management algorithms, analyze patient responses, and evaluate outcomes so that successful patient management is realized.

Su and Juestel (2010) state that clinical simulations are capable of honing critical thinking and clinical judgment and the clinical decision-making will increase according to experience (Lake, Moss, \& Duke, 2009; Tanner, 2006). Simulation is also able to improve psychomotor abilities, self-confidence, and clinical judgment (Bambini, Washburn, \& Perkins, 2009), as well as able to improve critical thinking, performance skills, knowledge, and clinical reasoning from the subject matter (Lapkin et al., 2010). Clinical judgment is often described as a synonym of a combination of critical thinking and clinical reasoning (Lindsey \& Jenkins, 2013), while these factors, i.e., psychomotor, cognitive, affective, non-clinical skills (teamwork, decision-making, planning), emotional status, personality traits, environmental factors, psychological, and physical status are all factors that affect performance (Ten Cate, Snell, \& Carraccio, 2010). Performance is a competency that can be considered as specific behavior (behavior) and also referred to as actual behavior in certain situations (Thompson \& Dowding, 2002). Education, training, and competence are mandatory requirements for all health staff in conducting the assessment and monitoring of acutely sick patients, clinical staff for EWS 
scores of seven or more should have competency in critical nursing expertise and airway management (Royal College of Physician, 2017).

\section{CONCLUSION}

The result of this study showed that there was a significant difference in nurses' clinical performance between the intervention and the control groups after the implementation of EWS tutorial simulation. In terms of knowledge, there was no significant difference between the groups. This EWS simulation tutorial can be used as an optional training method to improve clinical performance among nurses. Future studies should consider the modification of the intervention in the duration and post-test measurement for better outcomes.

\section{ACKNOWLEDGMENT}

This research project was funded by the Health Human Resources Development and Empowerment Agency of the Indonesian Ministry of Health.

\section{CONFLICT OF INTEREST}

None.

\section{REFERENCES}

Alam, N., Vegting, I. L., Houben, E., van Berkel, B., Vaughan, L., Kramer, M. H. H., \& Nanayakkara, P. W. B. (2015). Exploring the performance of the National Early Warning Score (NEWS) in a European emergency department. Resuscitation, 90, 111-115.

Bambini, D., Washburn, J., \& Perkins, R. (2009). Outcomes of clinical simulation for novice nursing students: Communication, confidence, clinical judgment. Nursing Education Perspectives, 30(2), 79-82.

Bick, D. E., Beake, S., Hundley, V., van Tiejlingen, E., Sheppard, Z. A., Thomas, S., \& Smith, G. B. (2014). A national cross-sectional survey of heads of midwifery services of uptake, benefits and barriers to use of obstetric early warning systems (EWS) by midwives. Midwifery, 30(11), 1140-1146.

Billings, D. M., \& Halstead, J. A. (2016). Teaching in nursing: A guide for faculty. ( $5^{\text {th }}$ ed.). United States of America: Elsevier.

Boyatzis, R. E. (1982). The component manager: A model for effective performance. New York: John Wiley \& Sons.

Bradshaw, M. J. \& Hultquist, B. L. (2017). Innovative teaching strategies in nursing and related health professions. ( $7^{\text {th }}$ ed.). United States of America: Jones \& Bartlett Learning.

Cahill, H., Jones, A., Herkes, R., Cook, K., Stirling, A., Halbert, T., ... Gattas, D. J. (2011). Introduction of a new observation chart and education programme is associated with better rates of vital-sign ascertainment in hospital wards. BMJ Quality and Safety, 20(9), 791-796.

Corfield, A. R., Lees, F., Zealley, I., Houston, G., Dickie, S., Ward, K., \& McGuffie, C. (2014). Utility of a single early warning score in patients with sepsis in the emergency department. Emergency Medicine Journal, 31(6), 482-487.

Curtin, L. B., Finn, L. A., Czosnowski, Q. A., Whitman, C. B., \& Cawley, M. J. (2011). Computer-based simulation training to improve learning outcomes in mannequin- 
based simulation exercises. American Journal of Pharmaceutical Education, 75(6), 113. doi:10.5688/ajpe756113

De Meester, K., Verspuy, M., Monsieurs, K. G., Van Bogaert P. (2013). SBAR improves nurse-physician communication and reduces unexpected death: A pre and post intervention study. Resuscitation, 84(9), 1192-1196.

Fagan, K., Sabel, A., Mehler, P. S., \& MacKenzie, T. D. (2012). Vital sign abnormalities, rapids respon, and adverse outcomes in hospitalized patients. American Journal of Medical Quality, 27(6), 480-486.

Gantt, L. T. (2010). Using the Clark simulation evaluation rubric with associate degree and baccalaureate nursing students. Nursing Education Perspectives, 31(2), 101105.

Jeffries, P. R. (2016). The NLN Jeffries simulation theory. New York, NY: National League of Nursing.

Khan, K., \& Ramachandran, S. (2012). Conceptual framework for performance assessment: Competency, competence and performance in the context of assessments in healthcare-Deciphering the terminology. Medical Teacher, 34(11), 920-928.

Lake, S., Moss, C., \& Duke, J. (2009). Nursing prioritization of the patient need for care: A tacit knowledge embedded in the clinical decision-making literature. International Journal of Nursing Practice, 15(5), 376-388.

Lapkin, S., Levett-jones, T., \& Bellchambers, H. (2010). Effectiveness of patient simulation manikins in teaching clinical reasoning skills to undergraduate nursing students: A systematic review. Clinical Simulation in Nursing, 6(6), e207-e222.

Law, A. M. (2014). A tutorial on design of experiments for simulation modeling. Proceedings of the Winter Simulation Conference 2014 (pp.66-80). Savanah, GA, USA: IEEE. doi:10.1109/WSC.2014.7019878

Liaw, S. Y., Chan, S. W. C., Chen, F. G., Hooi, S. C., \& Siau, C. (2014). Comparison of virtual patient simulation with Mannequin-based simulation for improving clinical performances in assessing and managing clinical deterioration: Randomized controlled trial. Journal of Medical Internet Research, 16(9), e214.

Liaw, S. Y., Wong, L. F., Lim, E. Y. P., Ang, S. B. L., Mujumdar, S., Ho, J. T. Y., ... \& Ang, E. N. (2016). Effectiveness of a web-based simulation in improving nurses' workplace practice with deteriorating ward patients: A pre- and post intervention study. Journal of Medical Internet Research, 18(2), e37.

Lindsey, P. L., \& Jenkins, S. (2013). Nursing students' clinical judgment regarding rapids response: The influence of a clinical simulation education intervention. Nursing Forum, 48(1), 61-70. doi:10.1111/nuf.12002

Ludikhuize, J., Smorenburg, S. M., de Rooij, S. E., \& de Jonge, E. (2012). Identification of deteriorating patients on general wards; measurement of vital parameters and potential effectiveness of the modified early warning score. Journal of Critical Care, 27(4), 424.e7-424.e13.

Meakim, C., Boese, T., Decker, S., Franklin, A.E, Gloe, D., Lioce, L, ...\& Borum, J. C. (2013). Standart of the best practice: Simulation standart I: Terminology. Clinical Simulation in Nursing, 9, S3-S11. doi:10. 1016j.ecns.2013.04.001

National Clinical Effectiveness Committee. (2014). Second Annual Report 2014. An Roinn Slainte Department of Health. Retrieved from https://assets.gov.ie/11508/bd7e535c192f4c49984e4fc4517cfb41.pdf 
Ogilvie, S., Cragg, B., Foulds, B. (2011). Perceptions of nursing students on the process and outcomes of a simulation experience. Nurse Educator, 36(2), 56-8. doi:10.1097/NNE.0b013e31820b4fd5.

Ozekcin, L. R., Tuite, P., Willner, K., \& Hravnak, M. (2015). Simulation education: Early identification of patient physiologic deterioration by acute care nurses. Clinical Nurse Specialist, 29, 166-173. Doi:10.1097/NUR.0000000000000123

Rabøl, L. I., Andersen, M. L., Østergaard, D., Bjørn, B., Lilja, B., \& Mogensen, T. (2011). Descriptions of verbal communication errors between staff. An analysis of 84 root cause analysis-reports from Danish hospitals. BMJ Quality \& Safety, 20(3), 268274. doi:10.1136/bmjqs.2010.040238

Royal College of Physicians. (2017). National Early Warning Score (NEWS) 2. Standardising the assessment of acute-illness severity in the NHS updated report of a working party-executive summary and recommendations. Retrieved from https://www.rcplondon.ac.uk/projects/outputs/national-early-warning-score-news2

Saab, M. M., McCarthy, B., Andrews, T., Savage, E., Drummond, F. J., Walshe, N., ...\& Hegarty, J. (2017). The effect of adult early warning systems education on nurses' knowledge, confidence, and clinical performance: A systematic review. Journal of Advanced Nursing, 73(11), 2506-2521.

Scalese, R. J., Obeso, V. T., \& Issenberg, S. B. (2008). Simulation technology for skills training and competency assessment in medical education. Journal of General Internal Medicine, 23(Suppl 1), 46-49.

Su, W. M., \& Juestel, M. J. (2010). Direct teaching of thinking skills using clinical simulation. Nurse Educator, 35(5), 197-204.

Taenzer, A. H., Pyke, J. B., \& McGrath, S. P. (2011). A review of current and emerging approaches to address failure-to-rescue. Anaesthesiology, 115(2), 421-431.

Tanner, C. A. (2006). Thinking like a nurse: A research based model of clinical judgment in nursing. Journal of Nursing Education, 45(6), 204-211.

Ten Cate, O., Snell, L., Carraccio, C. (2010). Medical competence: The interplay between individual ability and the health care environment. Medical Teacher, 32(8), 669675. doi:10.3109/0142159X.2010.500897

Thomson, C., \& Dowding, D. (2002). Clinical decision-making and judgement in nursing. London: Churchill Livingstone.

Zhang, Z., Luk, W., Arthur, D., \& Wong, T. (2001). Nursing competencies: Personal characteristics contributing to effective nursing performance. Journal of Advanced Nursing, 33(4), 467-474. 